weight of $7 . \mathrm{r} \mathrm{kg}$. The growth rates were very low, the animals reaching the weight of $22-23 \mathrm{~kg}$ at six months, $60 \mathrm{~kg}$ at I 2 months and Ioo kg at i 8 months. Some data uneasily collected on the field confirm the restricted abilities of this breed as regards the current performance parameters. According to this it may be asked whether this population presents any interest. The answer is yes. The scientist may indeed use the isolated situation of Corsican pig production to develop simple and unexpensive performance testing methods intended for more conventional environments. He may attempt to determine the specific abilities of the breed owing to which it has been able to persist despite the improved breeds. He may also attempt to promote a policy preconizing use of genotypes according to environments. In addition hardy breeds may be used as laboratory atrimals.

\title{
Heritability of individual performance in a pig herd Genetic significance of the deviation from batch average
}

\author{
J. NAVEAU, D. BONY \\ I.T.P., Centre Expérimental de Sélection Pen Ar Lan Maxent \\ 35380 Plélan-le-Grand (France) \\ A.C.T.A., I49, rue de Bercy, 75595 Paris Cedex I2
}

The heritability of 3 groups of Large White and Landrace pigs representing a totai of 50873 animals was calculated using the analysis of variance according to various hierarchical classification models.

The method of deviation from batch average (a birth to three week period) widely used in France for presenting the on-the farm tested individual performances involves a certain number of disadvantages. The batch average is not only the result of rearing conditions, but is also due to genetic factors. Consequently, it is not possible to compare the performances of animals from one batch to another, and even less from one herd to another. Nevertheless, the heritability values obtained with the less questionable method were very close to those classically found:

$$
\begin{aligned}
& h_{2}=0.20 \text { to } 0.25 \text { for growth and } \\
& h z=0.45 \text { to } 0.50 \text { for backfat thickness. }
\end{aligned}
$$

\section{Comparative study of fattening and fatness performance of entire males from three pig breeds according to terminal fattening weight}

\author{
J. P. RUNAVOT, R. KERISIT, Marie-Hélène LE TIRAN \\ I.T.P., Région Ouest, Service Sélection \\ La Motte-au-Vicomte, B.P. 3, 3565o Le Rheu (France)
}

A study concerning on the one hand the variation in the performances of three breeds: Large White, Landrace and Belgian Landrace during late fattening, and on the other hand, the consistence of performance test data until $90 \mathrm{~kg}$ live weight or $100 \mathrm{~kg}$ live weight, was made in young boar performance testing stations. The data collected from the 436 experimental animals showed that the correlations observed between the variables $90-100 \mathrm{~kg}$ and $35-90 \mathrm{~kg}$ were low (from 0.20 to 0.30 ).

These results emphasized the importance of late fattening and difficulty of extrapolating performance from 90 to $100 \mathrm{~kg}$. On the other hand, the fitting error was smaller from roo to $90 \mathrm{~kg}$.

Ranking of the animais until 90 or Ioo $\mathrm{kg}$ varied within reasonable limits (between 90 and 